Counsellia: Jurnal Bimbingan dan Konseling 8 (2) 135-141 | November 2018

Copyright (92017 Universitas PGRI Madiun

ISSN: 2088-3072 (Print) / 2477-5886 (Online)

Available online at: http://e-journal.unipma.ac.id/index.php/JBK

DOI: $10.25273 /$ counsellia.v8i2.3243

\title{
Profil Efikasi Diri Siswa MAN Wonokromo Bantul
}

\author{
Lintang Waskita Puri ${ }^{1}$, Budi Astuti ${ }^{2}$ \\ ${ }^{1}$ Pascasarjana Bimbingan dan Konseling, Universitas Negeri Yogyakrta, Yogyakarta \\ lintangwaskita1993@gmail.com \\ ${ }^{2}$ Pascasarjana Bimbingan dan Konseling, Universitas Negeri Yogyakrta, Yogyakarta \\ budi_astuti@uny.ac.id
}

\begin{abstract}
Abstrak
Efikasi diri dapat diartikan sebagai penilaian seseorang tentang kemampuan-kemampuan yang dimiliki individu dalam mencapai sesuatu yang telah ditargetkan. Penelitian ini bertujuan untuk memberikan penjelasan secara deskriptif tentang efikasi diri pada siswa, khususnya kelas VIII MAN Wonokromo Bantul.Metode penelitian yang digunakan dalam penelitian ini yaitu deskriptif kuantitatif. Subyek yang digunakan dalam penelitian ini adalah siswa kelas VIII MAN Wonokromo Bantul sejumlah 282 siswa. Teknik sampling yang digunakan dalam penelitian ini adalah simple random sampling. Teknik analisis data yang digunakan dalam penelitian ini adalah menggunakan statistik diskriptif berupa frekuensi dan persentase. Berdasarkan analisis dan pembahasan diperoleh hasil bahwa efikasi diri siswa kelas VIII MAN Wonokromo Bantul cenderung menunjukkan kategori sedang. Dari 142 siswa kelas VIII yang memiliki efikasi diri dengan kategori sangat rendah sebanyak 9 siswa (6,34\%), efikasi diri dengan kategori rendah sebanyak 35 siswa $(24,65 \%)$, efikasi diri dengan kategori sedang sebanyak 62 siswa $(43,66 \%)$, efikasi diri dengan kategori tinggi sebanyak 26 siswa $(18,31 \%)$ dan efikasi diri dengan kategori sangat tinggi sebanyak 10 siswa $(7,04 \%)$. Seyogyanya hasil penelitian ini dapat menjadi panduan bagi guru bimbingan dan konseling sebagai upaya untuk membantu meningkatkan efikasi diri siswa.
\end{abstract}

Kata Kunci: Efikasi Diri, MAN Wonokromo Bantul

\begin{abstract}
Self-efficacy can be interpreted as someone's assessment of the abilities that individuals have in achieving something that has been targeted. This study aims to provide a descriptive explanation of self-efficacy in students, especially grade VIII MAN Wonokromo Bantul. The research method used in this study is quantitative descriptive. The subjects used in this study were eighth grade students of MAN Wonokromo Bantul totaling 282 students. The sampling technique used in this study is simple random sampling. The data analysis technique used in this study is using descriptive statistics in the form of frequency and percentage. Based on the analysis and discussion, the results showed that the self-efficacy of eighth grade students of MAN Wonokromo Bantul tended to show moderate categories. Based on 142 class VIII students there were students who had self-efficacy in the very low category as many as 9 students (6.34\%), self-efficacy in the low category as many as 35 students (24.65\%), self-efficacy in the medium category of 62 students $(43,66 \%)$, self-efficacy in the high category as many as 26 students (18.31\%) and self-efficacy in the very high category as many as 10 students (7.04\%). The results of this study should be a guide for teachers guidance and counseling as an effort to help improve student self-efficacy.
\end{abstract}

Keywords : Self-Efficacy, MAN Wonokromo Bantul 



\section{PENDAHULUAN}

Sekolah menengah pertama berada pada fase remaja dimana perubahan dan perkembangan yang dialami menjadikannya berada pada masa yang banyak menarik perhatian. Masa remaja sebagai peralihan yang menyangkutpautkan antara masa kanak-kanak dan dewasa (Santrock, 2014). Tugas perkembangan yang seharusnya dimiliki pada remaja salah satunya memiliki penerimaan diri dan keyakinan akan kemampuan yang telah dimiliki (Juntika \& Yusuf, 2010). Namun, tidak semua remaja memiliki keyakinan akan kemampuan yang telah dimiliki untuk mencapai sebuah tujuan.

Banyak fenomena yang menunjukkan kurangnya keyakinan dalam diri siswa. Seperti hasil penelitian dari Khaira (2017) menjelaskan sebanyak 30 siswa mudah cemas dan kurangnya rasa optimis saat mendapat tugas yang sulit dalam pembelajaran. Terlebih lagi berdasarkan hasil wawancara dengan guru BK di MAN Wonokromo Bantul bahwa masih terdapat siswa takut dalam menghadapi ulangan dan enggan mengungkapkan pendapat karena takut disalahkan oleh temantemannya. Kenyataan lebih lanjut seperti peristiwa yang terjadi pada salah satu sekolah di Sulawesi Selatan akibat rasa takut tidak lulus ujian, membuat beberapa siswa menangis dan pingsan (www.liputan6.com, diakses Minggu tanggal 12 Agustus 2018). Penjelasan peristiwa tersebut menunjukkan bahwa siswa merasa takut dan cemas karena tidak lulus ujian dipicu karena kurangnya keyakinan akan kemampuan yang dimiliki oleh siswa. Keyakinan tersebut disebut dengan efikasi diri.

Omrod (2016:130) efikasi diri adalah menilai tentang seberapa besar kemampuan individu untuk mencapai target yang ditentukan (Ormod, 2016). Adapun pendapat Friedman \& Schustack (2016) mendefinisikan efikasi diri sebagai harapan serta keyakinan tentang seberapa kompeten individu dapat berperilaku pada setiap situasi. Schultz dan Schultz (2012) menambahkan bahwa efikasi diri adalah perasaan seseorang terhadap ketepatan dalam melakukan sesuatu dan kekuatan seseorang untuk menjalani kehidupan. Jadi, dapat diartikan efikasi diri sebagai penilaian seseorang tentang kemampuan-kemampuan yang dimiliki individu dalam mencapai sesuatu yang telah ditargetkan.

Efikasi diri penting untuk dimiliki semua siswa karena dengan efikasi diri seseorang dapat memainkan peran utama bagaimana individu dalam mencapai tujuan dan menghadapi tantangan (Saeid \& Eslaminejad, 2017). MTD Training (2010) menjelaskan empat sumber dalam membangun efikasi diri yaitu, pengalaman keberhasilan, model 
sosial, persuasi sosial dan kondisi emosional. Pengalaman keberhasilan mengacu pada peningkatan efikasi diri seseorang yang tidak lepas dari pengalaman-pengalaman yang telah dialami. Model sosial merujuk pada kemampuan individu dalam melihat kesuksesan orang lain yang memiliki kemampuan yang sama dengan apa yang dimiliki individu.

Sumber persuasi sosial yaitu peningkatan efikasi diri melalui nasehat dari seseorang akan efektif ketika digunakan secara berulangulang pada aktivitas yang sama. Sedangkan kondisi emosional akan berpengaruh pada efikasi diri ketika mengalami tingkat emosi yang tinggi. Selain sumber-sumber yang dapat membangun keyakinan diri, dalam efikasi diri terdapat Aspekaspek yang perlu diketahui oleh seorang siswa. Aspek-aspek efikasi diri merupakan bagian dari sesuatu yang tidak dapat dipisahkan dari efikasi diri. Menurut Eggen dan Kauchak (2010) menjelaskan bahwa aspek-aspek dalam efikasi yaitu, orientasi tugas, usaha, kegigihan, keyakinan, penggunaan strategi, dan kinerja. Aspek-aspek dalam efikasi diri tersebut tidak dapat berdiri sendiri, melainkan antara satu dengan yang lain saling berhubungan dan saling tergantung antara satu dengan yang lain. Melalui aspek-aspek ini dapat membentuk tinggi dan rendahnya efikasi diri pada siswa.
Efikasi diri yang tinggi dapat dilihat ketika individu lebih menyukai tugas lebih menantang, lebih banyak mencoba dan tidak mudah menyerah (Titilayo, Oloyede, \& Adekunle, 2016; Saeid \& Eslaminejad, 2017). Siswa yang memiliki efikasi diri akan menyelesaikan setiap tantangan dengan baik tetapi mereka yang memiliki efikasi diri yang rendah ketika menghadapi masalah akan berhenti untuk mencoba. Myers (2010) menambahkan bahwa tingginya efkasi diri dapat terlihat saat siswa lebih banyak mencoba, tidak mengalami kecemasan dan depresi, sehingga pola hidupnya lebih sehat dan memiliki tujuan hidup yang jelas. Namun, rendahnya efikasi diri akan terlihat ketika seseorang putus asa dan menganggap berbagai pekerjaan yang ada disekitarnya tidak mampu siswa kerjakan dengan baik (Ghufron \& Rini, 2010). Rendahnya efikasi diri dapat terlihat ketika siswa dihadapkan dengan tugas yang sukar akan memiliki pikiran negatif dan memikirkan tuntutan tugas sebagai ancaman, mudah stres dan membuat tugas-tugas menjadi lebih sulit (Binnaz, Duygu, \& Mehtap, 2017; Yusuf, 2011).

Rendahnya efikasi diri yang dimiliki oleh siswa jika dibiarkan dapat berdampak pada pencapaian nilai-nilai akademis peserta didik. Hasil penelitian Asakereh \& Nouroddin (2018) Hubungan yang signifikan diamati antara efikasi diri 
dan prestasi akademik. Tingginya efikasi diri, akan berkaitan dengan tinggi prestasi akademik. Namun, rendahnya efikasi diri, dapat berdampak pada rendahnya prestasi akademik. Tingkat efikasi diri juga akan berpengaruh pada kecemasan berbicara di depan umum.

Penelitan Djayanti \& Rina (2015) menunjukkan adanya korelasi negatif antara efikasi diri dengan kecemasan berbicara di depan umum, yang artinya apabila efikasi diri tinggi maka kecemasan berbicara di depan umum rendah. Begitu juga sebaliknya, apabila efikasi diri rendah maka kecemasan berbicara di depan umum tinggi. Munculnya ketidakyakinan dalam diri individu menyebabkan adanya ketegangan dalam dirinya sehingga menimbulkan kecemasan. Sedangkan dari penelitian Husain (2014) menjelesakan bahwa adanya hubungan yang signifikan antara efikasi diri dengan motivasi berprestasi. Hal ini berarti bahwa siswa dengan keyakinan yang tinggi akan mampu menjadi penentu motivasi mereka untuk berprestasi.

Berbagai fenomena di atas mendasari peneliti dalam melakukan penelitian ini. Penelitian ini bertujuan untuk memberikan penjelasan secara deskriptif tentang efikasi diri pada siswa, khususnya kelas VIII MAN Wonokromo Bantul. Efikasi diri yang rendah pada siswa sangat penting untuk diketahui agar dilakukan upaya untuk meningkatkan efikasi diri siswa melalui layanan konseling teknik tertentu.

\section{METODE PENELITIAN}

Penenlitian ini merupakan penelitian dengan menggunakan pendekatan kuantitatif karena dalam penelitian ini lebih menekankan analisisnya dengan data-data numerikal. Metode penelitian yang digunakan dalam penelitian ini yaitu deskriptif kuantitatif. Melalui metode penelitian deskriptif kuantitatif dapat diperoleh deskripsi mengenai efikasi diri pada siswa MAN Wonokromo Bantul, khususnya pada kelas VIII. Populasi dalam penelitian ini sebanyak 282 siswa. Adapun cara dalam penentuan sampel, peneliti menggunakan cara. simple random sampling. Jumlah sampel dalam penelitian ini sebanyak 142 siswa. Metode pengumpulan data yang digunakan dalam penelitian ini menggunakan metode skala sebagai metode untuk memperoleh data yang berkaitan tentang efikasi diri. Skala efikasi diri yang disusun dalam penelitian ini menggunakan alternatif jawaban, yaitu sangat tinggi, tinggi, sedang, rendah, dan sangat rendah. Teknik analisis data yang digunakan dalam penelitian ini adalah menggunakan statistik diskriptif. Perhitungan statistik deskriptif brupa frekuensi dan persentase yang didapat dari hasil penelitian. 


\section{HASIL DAN PEMBAHASAN}

Berdasarkan data yang diperoleh terkait efikasi diri siswa dapat dikateogorisasikan menjadi menjadi lima kategori, yaitu kategori sngat rendah, rendah, sedang, tinggi, sangat tinggi. Berikut deskripsi efikasi diri siswa MAN Wonokromo Bantul dapat dilihat pada tabel 1 berikut ini.

\section{Tabel 1}

Distribusi Frekuensi Efikasi Diri

\begin{tabular}{cccc}
\hline$\leq 103,19$ & 9 & $6,34 \%$ & Sangat Rendah \\
\hline $\begin{array}{c}103,20 \text { s.d. } \\
\leq 112,68\end{array}$ & 35 & $24,65 \%$ & Rendah \\
\hline $\begin{array}{c}112,69 \text { s.d. } \\
\leq 122,16\end{array}$ & 62 & $43,66 \%$ & Sedang \\
\hline $\begin{array}{c}122,17 \text { s.d } \\
\leq 131,65\end{array}$ & 26 & $18,31 \%$ & Tinggi \\
\hline$>131,66$ & 10 & $7,04 \%$ & Sangat Tinggi \\
\hline
\end{tabular}

Berdasarkan tabel di atas dapat diketahui bahwa dari jumlah total 142 siswa, terdapat sejumlah siswa berada dalam kategori sangat rendah sebanyak 9 siswa $(6,34 \%)$. Siswa dengan efikasi diri rendah sebanyak 35 siswa $(24,65 \%)$. Siswa dengan efikasi sedang sebanyak 62 siswa $(43,66 \%)$. Siswa dengan tingkat efikasi tinggi sebanyak 26 siswa $(18,31 \%)$. Siswa yang memiliki efikasi sangat tinggi sebanyak 10 siswa $(7,04 \%)$. Hal ini berarti efikasi diri yang dimiliki oleh siswa MAN Wonokromo Bantul mempunyai kecenderungan sedang yaitu sejumlah 62 siswa $(43,66 \%)$.

Deskripsi selanjutnya mengenai persentase efikasi diri siswa pada masing-masing indikator dapat dilihat pada gambar berikut.

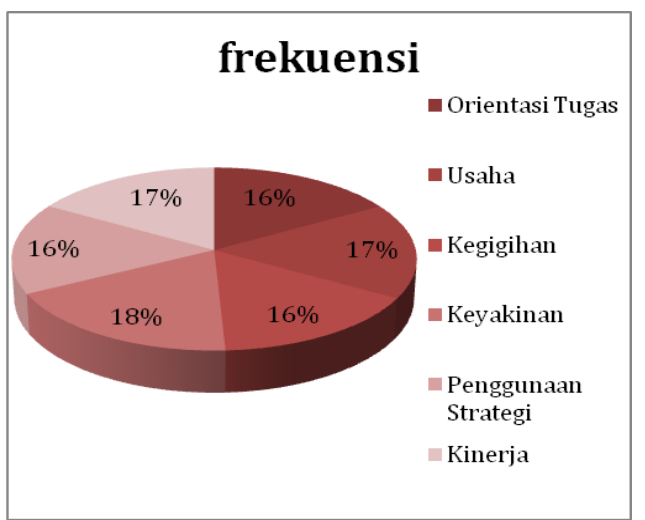

Gambar 1. Persentase Efikasi Diri Siswa pada Masingmasing Indikator

Berikut penjelasan pada masingmasing indikator tersebut:

\section{Orientasi tugas}

Individu berani menerima tugastugas menantang yang dapat meningkatkan keyakinan akan kemampuan yang dimiliki. Aspek oientasi pada tugas memberikan kontribusi pada efikasi diri siswa di MAN Wonokromo Bantul sebanyak $16 \%$. 


\section{Usaha}

Individu mampu mengeluarkan usaha yang tinggi ketika dihadapkan dengan tugas-tugas dan mampu menilai kemampuan terhadap tugas-tugas yang dapat diselesaikan. Aspek usaha yang besar dalam menghadapi tantangan memberikan kontribusi pada efikasi diri siswa MAN Wonokromo Bantul sebanyak $17 \%$.

\section{Kegigihan}

Kegigihan dalam mempertahankan tujuan meskipun tujuan tidak sesuai dengan harapan. Aspek kegigihan yang besar memberikan kontribusi pada efikasi diri siswa MAN Wonokromo Bantul sebanyak $16 \%$.

\section{Keyakinan}

Keyakinan untuk mencapai keberhasilan, kemampuan dalam mengontrol stress dan kecemasan ketika tujuan tidak dapat terpenuhi dan memiliki keyakinan dalam mengendalikan keadaan sekitar. Aspek keyakinan akan keberhasilan memberikan kontribusi pada efikasi diri siswa MAN Wonokromo Bantul sebesar $18 \%$.

\section{Penggunaan strategi}

Kemampuan individu dalam merancang strategi untuk mencapai tujuan yang telah ditetapkan. Aspek penggunaan strategi memberikan kontribusi dalam efikasi diri siswa MAN

Wonokromo Bantul sebanyak $16 \%$.

\section{Kinerja}

Individu menunjukkan kinerja yang tinggi. Aspek kinerja memberikan kontribusi pada efikasi diri siswa MAN Wonokromo Bantul sebanyak $17 \%$.

Penelitian Putri menyatakan bahwa siswa kelas $\mathrm{X}$ SMK Sahid Jakarta, memiliki efikasi yang rendah. Hal ini ditunjukkan dari banyak siswa yang mengeluh jika diberikan tugas, merekamengatakan bahwa tugas itu sulit sebelum mereka mengerjakannya, beberapa siswa terlihat kurang antusias saat proses belajar. Penelitian di atas menunjukkan bahwa permasalahan terkait efikasi diri siswa selalu ada pada setiap sekolah, salah satunya di MAN Wonokromo Bantul

\section{SIMPULAN}

Berdasarkan hasil penelitian dapat tergambar bahwa efikasi diri siswa kelas VIII MAN Wonokromo Bantul cenderung menunjukkan kategori sedang. Pernyataan tersebut dibuktikan dari hasil analisis data efikasi diri siswa. Siswa dengan kategori sangat rendah sebanyak 9 siswa $(6,34 \%)$. Siswa dengan efikasi diri rendah sebanyak 35 siswa $(24,65 \%)$. Siswa dengan efikasi sedang sebanyak 62 siswa $(43,66 \%)$. Siswa dengan tingkat efikasi tinggi 
sebanyak 26 siswa (18,31\%). Siswa yang memiliki efikasi sangat tinggi sebanyak 10 siswa (7,04\%). Guru BK diharapkan dapat menggunakan hasil penelitian ini sebagai sumber dalam membantu meningkatkan efikasi diri siswa.

\section{DAFTAR PUSTAKA}

Bandura, Albert. (1997). Selfefficacy - The Exercise of Control. New York: W.H. Freeman and Company.

Djayanti, Wifa \& Rina Rahmatika. (2015). Hubungan Antara Efikasi Diri Dengan Kecemasan Berbicara di Depan Umum Pada Mahasiswi. Jurnal Psikogenesis, 3: 187-198.

Eggen, P., \& Kauchak, D. (2010). Educational Psychology Windows on ccassrooms. Eight Edition. Boston: Pearson.

Friedman, Howard \& Schustack, Miriam. (2016). Personality Classic Theories and Modern Research.

Boston: Pearson/Allyn and Bacon.

Ghufron, M. Nur., \& Rini Risnawati S. (2010).Teori-Teori Psikologi. Ar-ruzz Media Group: Yogyakarata.

https://www.liputan6.com/news/read /268688/menjelang-un-siswadihantui-kecemasan-taklulus. Diakses Minggu tanggal 12 Agustus 2018.

Husain, Urfi Khalid. (2014). Relationship between SelfEfficacy and Academic Motivation. Journal
Education and Humanities, 2: 35-39.

Juntika, Nurihsan \& Yusuf, Syamsu. (2010). Landasan Bimbingan dan Konseling. Bandung: PT. Remaja Rosdakarya.

Khaira, Riska Ana. (2017). Profil Efikasi Diri Siswa dalam Pembelajaran Fisika Di SMA $N 3$ Banda Aceh. Jurnal Psikologika, 2: 127-135.

MTD Training. (2010). Personal Confidence and Motivation. Dapat diakses dari: BookBooN.com

Myers, E. G. (2010). Social Psychology. New York. Mc Graw-Hill.

Putri, Melisa. (2018). Tingkat Efikasi Diri Siswa Kelas X SMK Sahid Jakarta. (Skripsi, Universitas Sanata Dharma).

Santrock,J.W. (2014). Adolescence fifteenth edition. USA: McGraw-HillEducation.

Schultz, D., \& Schultz, E. S. (2010). Psychology and work today (10 edition). NewYork: Pearson.

Schultz, D., \& Schultz, S.E. (2012). Theories of Personality.USA: Wadsworth, Inc. 